\title{
Why the patients with Hirayama disease have abnormal cervical sagittal alignment? A radiological measurement analysis of posterior cervical extensors
}

\author{
Ye $\operatorname{Tian}^{\dagger}$, Lin Xie ${ }^{\dagger}$, Jianyuan Jiang ${ }^{*}$ and Hongli Wang ${ }^{*}$
}

\begin{abstract}
Purpose: To explore the relationship between the strength of posterior cervical extensors (PCEs) and cervical sagittal alignment in Hirayama disease (HD) patients.

Methods: We analyzed the (magnetic resonance imaging) MRI T2WI and X-rays of $60 \mathrm{HD}$ patients who visited Huashan Hospital from June 2017 to February 2020. Symptoms of these patients include adolescent onset, manifestation of unilateral upper limb muscle weakness and muscle atrophy of the forearm and hand. MRI images were used to measure (the cross-sectional area) CSA of cervical PCEs. The ratio of muscle CSA to vertebral body areas at the same level is defined as R-CSA. Cervical sagittal alignment includes the $\mathrm{C}_{2-7}$ Cobb angle, $T 1$ slope and $\mathrm{C}_{2-7}$ sagittal vertical axis (SVA). The geometric center of the $C_{3-6}$ vertebral body was determined using the line connecting the $C_{2}$ inferior endplate and the $C_{7}$ upper endplate. When located behind the line, it is defined as a "local kyphotic deformity."The number of vertebral bodies involved in kyphotic deformity was determined by measuring the local kyphosis angle (LKA). Spearman correlation analysis $(a=0.05$ ) was used to determine the relationship between R-CSA and sagittal parameters. ROC curves were used to analyze the sensitivity and specificity of relevant variables.
\end{abstract}

Results: Spearman correlation test revealed that R-CSA negatively correlated with T1S $(S=0.34, r=0.34, p=0.01)$ and LKA $(S=0.44, r=0.5, p=0.01)$, but did not correlate with the C2-C7 Cobb angle ( $S=0.20, p=0.12)$ or C2-C7 SVA $(S=-0.17, p=0.46) .(p<0.05)$. ROC curve analysis showed that the areas under the curve (AUCs) of the T1 slope and LKA was 0.6696 and 0.7646 , respectively. T1 slope, cutoff value: $17.2^{\circ}$; sensitivity: 0.5806 ; specificity: $0.7241 ; p<0.05$. LKA: cutoff value: $-14^{\circ}$; sensitivity: 1 ; specificity: $0.5333 ; p<0.05$.

Conclusions: In patients with Hirayama disease, the strength of posterior cervical extensors and cervical sagittal alignment are closely related. The local kyphosis angle can be used as a reference for the strength of posterior cervical extensors. These results indicate the weakness of PCEs, which may predispose the cervical spine of HD patients to a less stable situation. Therefore, patients with Hirayama disease should strengthen the exercise of the PCEs.

Keywords: Hirayama disease, Cervical spine, Posterior cervical extensors, Cross-sectional area, Local kyphotic deformity

\footnotetext{
*Correspondence: 20211220061@fudan.edu.cn; wanghongli@huashan.org. cn

${ }^{\dagger}$ Ye Tian and Lin Xie are co-first authors. Department of Orthopedics, Huashan Hospital, Fudan University, Spinal Center Fudan University, 12 Mid-Wulumuqi Road, Shanghai 200040, China
} Introduction

Hirayama disease (HD), first reported in 1959 [1], is a spinal cord-derived upper extremity muscular atrophy disease that commonly affects adolescent males. Although original author(s) and the source, provide a link to the Creative Commons licence, and indicate if changes were made. The images or other third party material in this article are included in the article's Creative Commons licence, unless indicated otherwise in a credit line to the material. If material is not included in the article's Creative Commons licence and your intended use is not permitted by statutory regulation or exceeds the permitted use, you will need to obtain permission directly from the copyright holder. To view a copy of this licence, visit http://creativecommons.org/licenses/by/4.0/. The Creative Commons Public Domain Dedication waiver (http://creativeco mmons.org/publicdomain/zero/1.0/) applies to the data made available in this article, unless otherwise stated in a credit line to the data. 
HD is thought to be most prevalent among Asians, cases have been reported in many parts of the world [2-5]. A high number of cases are expected in the next few decades. There is evidence that early surgical intervention is effective in managing HD [6-9]. Thus, spine surgeons will be expected to master HD diagnosis and treatment. In HD patients, the sagittal sequence of the cervical vertebra is abnormal and the cervical vertebra's range of motion is increased [10]. Here, we sought to uncover the causes for this.

Neck muscles are crucial in the maintenance of cervical spine stability [11]. In normal spines, static sagittal balance is the spine's physiological alignment by muscle forces [12]. Hence, spine sagittal balance is an important factor affecting patient quality of life and surgical outcomes [13]. The cervical spine is the most flexible part of the spine and provides support to the skull to maintain horizontal fixation. Numerous factors affect cervical sagittal balance, especially muscle strength, and extensor muscles have been shown to be crucial for this [14]. However, the cause of cervical sagittal alignment abnormalities in HD is unknown. We speculate that it is associated with the strength of PCEs. It is known that muscle CSA positively correlates with muscle strength $[15,16]$. Manually delineating regions of interest (ROIs) in extensor posterior cervix on axial MRI and then measuring the CSA of the PCEs have been shown in many studies with good consistency $[17,18]$.

Here, we investigated correlation between the cervical sagittal alignment and PCEs and examined the importance of cervical muscle training in the treatment of HD.

\section{Materials and methods}

The study was approved by the institutional ethics board (No: 2021-582, Institutional Review Board of Huashan Hospital, Fudan University) and performed in accordance with the ethical standards of the 1964 Declaration of Helsinki as revised in 2000 and those of Good Clinical Practice. All patients gave written informed consent. Participants under the age of 16 obtained written informed consent from their parents or guardians.

\section{Patients and methods}

The study involved male HD patients diagnosed at our hospital from June 2017 to February 2020. The diagnostic inclusion/exclusion criteria were as follows: The clinical diagnosis of Hirayama disease [1, 19-23] included adolescent onset, manifestation of unilateral upper limb muscle weakness and muscle atrophy of the forearm and hand. Accompanying symptoms included cold paralysis and tremor-like movement of fingers when stretched. Some patients with a longer course may have active or hyperactive tendon reflexes of the lower limbs,
Table 1 Parameters included in this study

\begin{tabular}{ll}
\hline Abbreviations & Definition \\
\hline CSA & Cross-sectional area \\
VBA & Vertebral body area \\
R-CSA & Relative cross-sectional area \\
CE* & Cervical extensors \\
SVA & Sagittal vertical axis \\
LKA & Local kyphosis angle \\
CL & Cervical lordosis \\
\hline
\end{tabular}

*CE include Des deep extensors, SEs superficial extensors

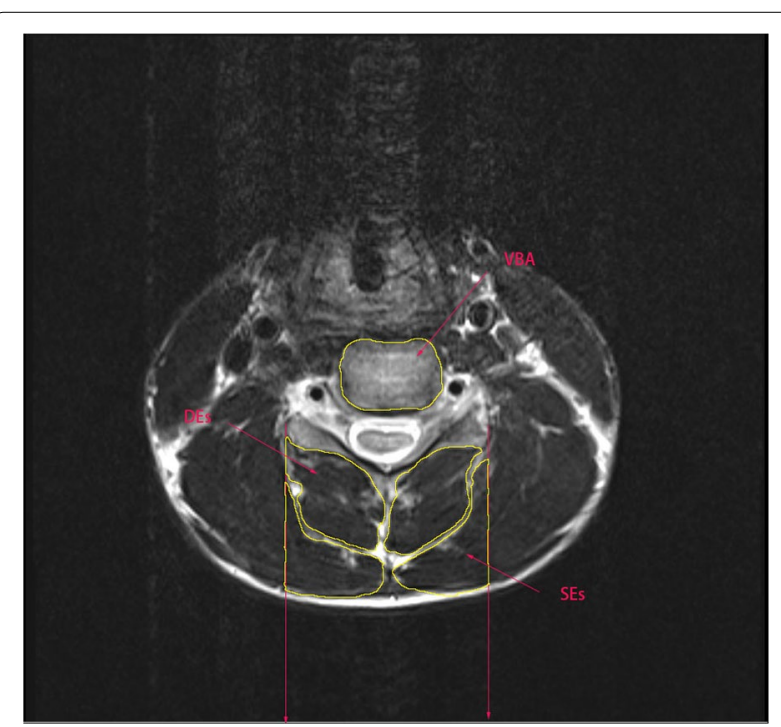

Fig. 1 Demonstration of measuring regions of intrest on T2-weighted axial MR

as well as positive Hoffmann's signs; male patients and age (15-25 years). A total of 60 patients with a mean age of 18.95 years (range $16-22$ years) who met the criteria were included in the study.

\section{Radiographic evaluations}

Muscle cross-sectional area was measured by two independent spine surgeons (Table 1), Tian and Xie, using the ImageJ (National Institutes of Health, America) to measure the ROI (Fig. 1) on the CSA of the PCEs based on the techniques used in previous studies [24]. Selected images were all T2-weighted magnetic resonance images (MRIs) parallel to the $\mathrm{C}_{5}-\mathrm{C}_{6}$ intervertebral disk axis MR. PCEs include deep extensors (DEs) and superficial extensors (SEs). The ROI was defined as the vertical line of the lateral edge of the bilateral facet joints. The CSA of the endplate at the same level was used as the c5-c6 vertebral body area, and the bilateral CSA was measured and recorded in $\mathrm{mm}^{2}$. Examination was performed using 
a 1.5 T MRI machine (Siemens, Germany) to acquire a neutral MRI of the cervical spine with the patient laying in the supine position.

Cervical sagittal parameters were measured on upright cervical radiographs (Fig. 2). The $\mathrm{C}_{2}-\mathrm{C}_{7} \mathrm{Cobb}$ angle was created by a line parallel to the inferior endplate of the $\mathrm{C}_{2}$ vertebra and a line parallel to the inferior endplate of the $\mathrm{C}_{7}$ vertebra. The SVA is the vertical distance from the plumb line of the geometric center of the $\mathrm{C}_{2}$ vertebra to the posterior superior corner of the $\mathrm{C}_{7}$ vertebra. $\mathrm{T} 1$ $\mathrm{s}$ is the angle between the horizontal and superior endplates of T1 s vertebra [25-27]. The definition for "local kyphotic deformity" was used to determine the upper/ lower end vertebras on upright cervical radiographs. Next, a vertical line was drawn at the upper/lower end vertebrae endplate extension lines. The resulting angle between the two vertical lines is the "local kyphosis angle" (LKA) and was measured using the Cobb method. When the extension line of the vertebral endplate intersected behind the neck, the Cobb angle was given a positive value, and when the extension line of the vertebral endplate intersected at the front of the neck, the Cobb angle was given a negative value. When the Cobb angle was a negative value, it was defined as LKA.

\section{Statistical analysis}

STATA version 16.0 (Stata Corp) was used for statistical analysis. All parametric results are expressed as the mean \pm standardized deviation. Spearman rank correlations were used for statistical analysis of correlations. $p<0.05$ indicated statistical significance. An independent $t$ test was used to compare differences of all these data (without LKA) between "local kyphotic deformity" and "non-local kyphotic deformity."

We defined R-CSA less than 3.396 (median) as a small area, and vice versa as a large area, and then, division of the data of T1 slope and LKD into two groups according to the R-CSA. The sensitivity of the assays was plotted against false positivity (1-specificity) using ROC curves using GraphPad Prism 8.0 (California, USA). Comparison of AUC was made, which compared the AUC to the diagonal line of no information (AUC 0.5). To determine the specificity and sensitivity of the assays, we took (1-specificity) as $\mathrm{x}$-axis and sensitivity as the $\mathrm{y}$-axis. If $\mathrm{AUC}=1.0$, the index was an ideal test, and if $\mathrm{AUC}<0.5$, the index had no reference value.

\section{Results}

A total of 60 male patients with a mean age of $(18.95 \pm 1.67)$ years (range 16-22) were included in the study. The mean height was $174.2 \pm 6.41(\mathrm{~cm})$ (range 150-188). The mean BMI (Body mass index) was $21.25 \pm 2.95$. The duration of disease was $4-6$ months. After our research, we divided the patients into two groups: non-LKD $(n=29)$ and LKD $(n=31)$. There were no differences in age, height, weight or BMI between the two groups $(p>0.05)$ (Table 3).

The area parameters were VBA: $384.623 \pm 64.70 \mathrm{~mm}^{2}$. CSA: $1348.98 \pm 236.44 \mathrm{~mm}^{2}$. R-CSA: $3.60 \pm 0.87 \mathrm{~mm}^{2}$. Cervical sagittal parameters were T1 slope: $16.62 \pm 5.96$, C2-C7 SVA: $17.40 \pm 8.73$ and C2-C7 Cobb: $5.28 \pm 12.43$ (Table 2). Of these, 31 had "LKD": $C_{3-5}: 2, C_{4-6}: 7, C_{3-6}$ : 22. LKA: $-9.82 \pm 6.33$. The $C_{2-7}$ Cobb angle of the LKD group was smaller than of the group non-LKD, and the VBA of the non-LKD group was smaller than that of the

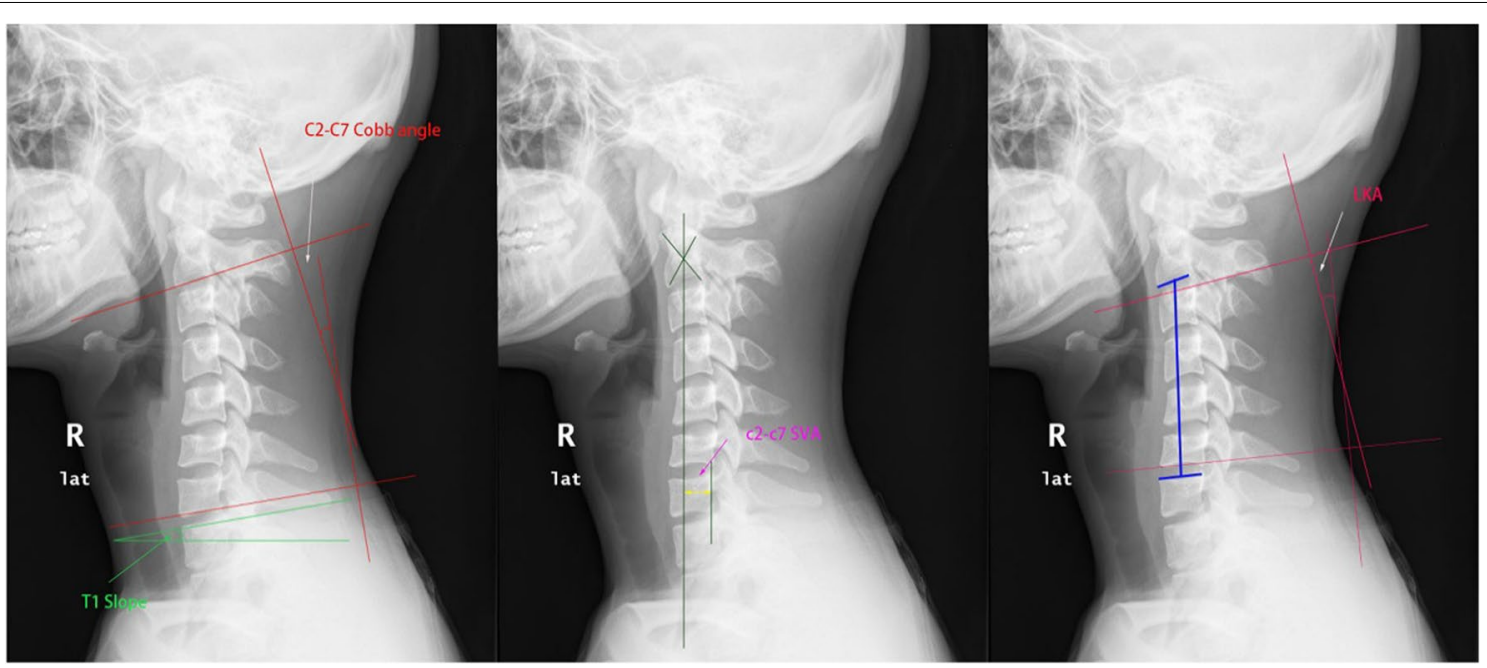

Fig. 2 Cervical sagittal parameters 
Table 2 Parametric results

\begin{tabular}{ll}
\hline Characteristics & Number* $^{*}$ \\
\hline No. of patients & 60 \\
Age $(\mathrm{yr})$ & $18.95 \pm 1.67$ \\
CSA $\left(\mathrm{mm}^{2}\right)$ & $1348.98 \pm 236.44$ \\
VBA $\left(\mathrm{mm}^{2}\right)$ & $384.62 \pm 64.70$ \\
R-CSA & $3.60 \pm 0.87$ \\
C2-C7 Cobb angle $\left(^{\circ}\right)$ & $5.28 \pm 12.43$ \\
T1 Slope $\left(^{\circ}\right)$ & $16.62 \pm 5.96$ \\
C2-C7 SVA $(\mathrm{mm})$ & $17.40 \pm 8.73$ \\
\hline
\end{tabular}

*Values are presented as mean \pm SD

LKD group. There was no difference in other parameters between the two groups (Table 3).

Correlation analyses were done performed using the Spearman test. R-CSA negatively correlated with T1S $(s=0.3362, p=0.0086)$, and R-CSA negatively correlated with LKA $(s=0.4382, p=0.0137)$. R-CSA did not correlate with the $\mathrm{C}_{2}-\mathrm{C}_{7}$ Cobb angle $(s=0.2029, p=0.1199)$ or $\mathrm{C}_{2}-\mathrm{C}_{7}$ SVA ( $\left.s=-0.1701, p=0.4586\right)$ (Fig. 3).

ROC curve analysis showed that the areas under the curve (AUCs) of T1 slope and LKA were 0.6696, 0.7646, respectively (Fig. 4a). T1 slope, cutoff value: $17.2^{\circ}$, sensitivity: $58.06 \%$; specificity: $72.41 \%, p<0.05$ (Fig. 4b). LKA: cutoff value: $-14^{\circ}$, sensitivity: $100 \%$, specificity: $53.33 \%$, $p<0.05$ (Fig. 4c).

\section{Discussion}

\section{Posterior cervical extensors and sagittal parameters}

Currently, the relationship between cervical sagittal alignment and PCEs has received attention from many scholars [28-30]. Past studies show that in some patients with non-Hirayama disease (HD) [11], cervical sagittal alignment is abnormal and accompanied by PCEs atrophy. There is a paucity of research on HD. In our study, we found similar results in HD patients. We utilized imaging parameters to describe cervical sagittal alignment and used the muscle cross-sectional area to represent muscle strength. These methods have been used in previous studies $[15,17]$.

\section{Strong PCEs may lead to better cervical sagittal alignment}

Cervical muscle strength is lower in HD patients than in normal people, and there is a mismatch between flexor muscles and extensor muscles [24]. Changes in extensor muscle strength may affect cervical sagittal alignment. T1 $\mathrm{s}$ is an important cervical sagittal parameter and is related to the thoracic entrance angle [31, 32]. The degree of motion of the thoracic vertebra is small and prone to change. Our data showed that T1s was closely related to the area of the PCEs (Fig. 3a). Since T1 s is a relatively fixed value [33], it was closely related to the entrance angle of the thoracic cage and not easily altered by changes in the cervical spine. Our data suggest that T1 s may not be affected by changes in the strength of the PCEs, but the larger the T1 s is, the more the cervical vertebrae are required to participate in lordosis to maintain horizontal gaze and larger cervical lordosis (CL) requires stronger support of the PCEs. At present, the relationship between T1 $\mathrm{s}$ and the strength of PCEs is unclear in HD patients. In the future, it may serve as an indicator of posterior cervical muscle strength. There was no obvious correlation between SVA and PCEs strength (Fig. 3b). Lee et al. showed that T1 s, CL and SVA are closely related, and that SVA has a compensatory role between T1 s and CL [33]. Thus, there was no clear correlation between SVA and PCEs strength.

The $\mathrm{C}_{2}-\mathrm{C}_{7}$ Cobb angle was smaller than that reported by past studies, but it did not significantly correlate with PCEs strength [34-36]. These figures are influenced by factors such as age and posture. According to a previous study [37], we predicted that Cobb angle might be closely related to the strength of PCEs, but corresponding results

Table 3 Comparison of all parameters of different muscles in two groups

\begin{tabular}{lcccc}
\hline & LKD $(\boldsymbol{n}=\mathbf{3 1})$ & Non-LKD $(\boldsymbol{n}=\mathbf{2 9})$ & $\boldsymbol{T}$ value & $\boldsymbol{p}$ Value \\
\hline Height & $175.03 \pm 1.07$ & $1.73 \pm 1.27$ & 1.17 & -0.25 \\
Weight & $64.18 \pm 2.018$ & $64.84 \pm 1.72$ & -1.06 & 0.25 \\
BMI & $20.86 \pm 0.50$ & $21.68 \pm 0.57$ & -0.02 & 0.29 \\
CSA $\left(\mathrm{mm}^{2}\right)$ & $1348.52 \pm 236.24$ & $1349.47 \pm 240.85$ & 2.15 & 0.99 \\
VBA $\left(\mathrm{mm}^{2}\right)$ & $401.46 \pm 72.62$ & $366.62 \pm 50.21$ & ${ }^{a} Z=-1.22$ & $0.04^{*}$ \\
R-CSA & $3.45 \pm 0.79$ & $3.76 \pm 0.94$ & ${ }^{2} Z=-4.42$ & 0.22 \\
C2-C7 Cobb angle $\left(^{\circ}\right)$ & $-1.41 \pm 8.19$ & $12.40 \pm 12.32$ & -1.94 & $0.00^{* *}$ \\
T1 slope $\left(^{\circ}\right)$ & $15.23 \pm 5.54$ & $18.11 \pm 5.91$ & -0.02 & 0.06 \\
C2-C7 SVA $(\mathrm{mm})$ & $17.37 \pm 7.72$ & $17.43 \pm 9.85$ & & 0.98 \\
\hline
\end{tabular}

${ }^{a}$ These data use Wilcoxon rank-sum test

${ }^{*} p<0.05,{ }^{* *} p<0.01$ 


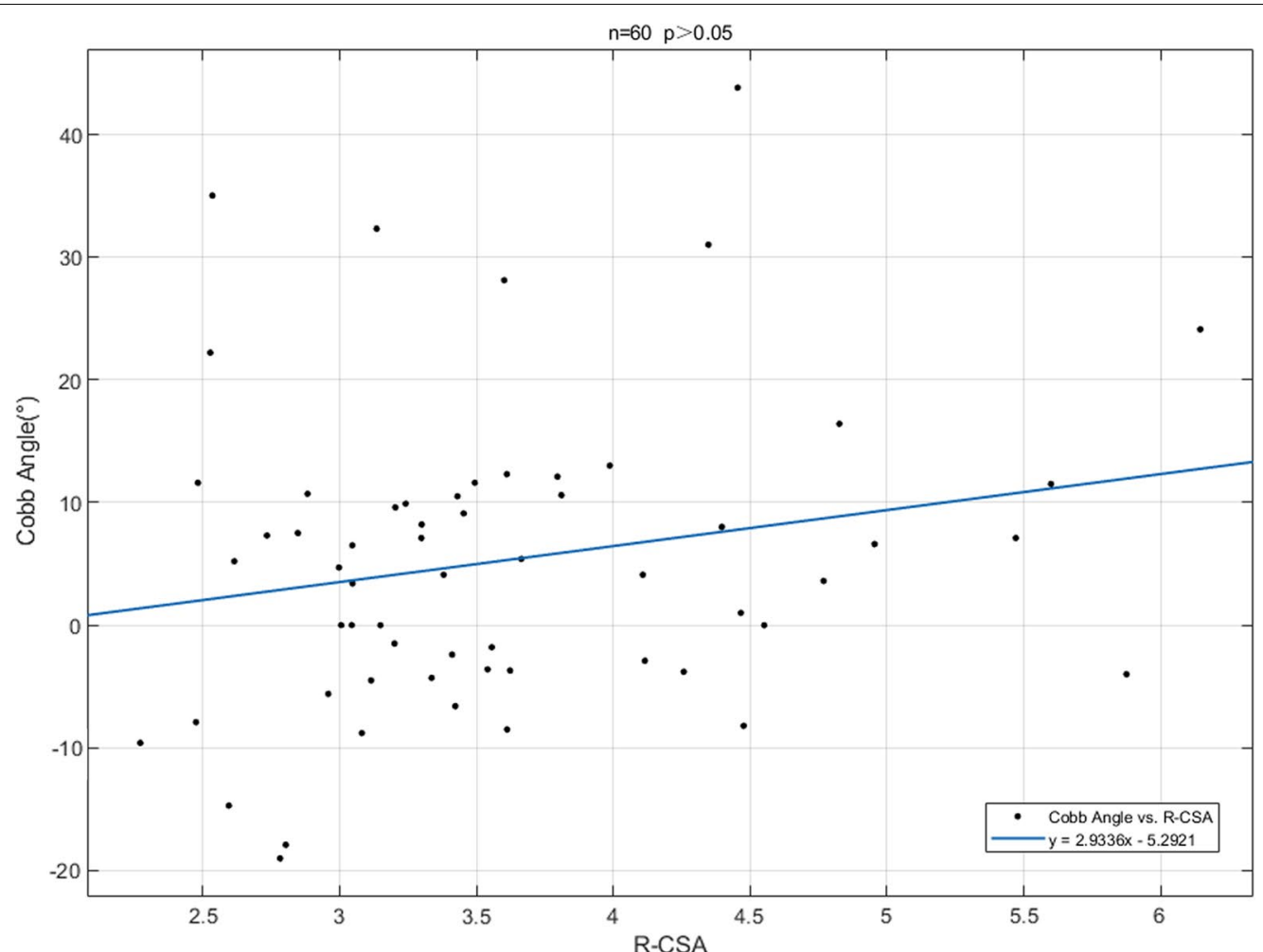

(a)

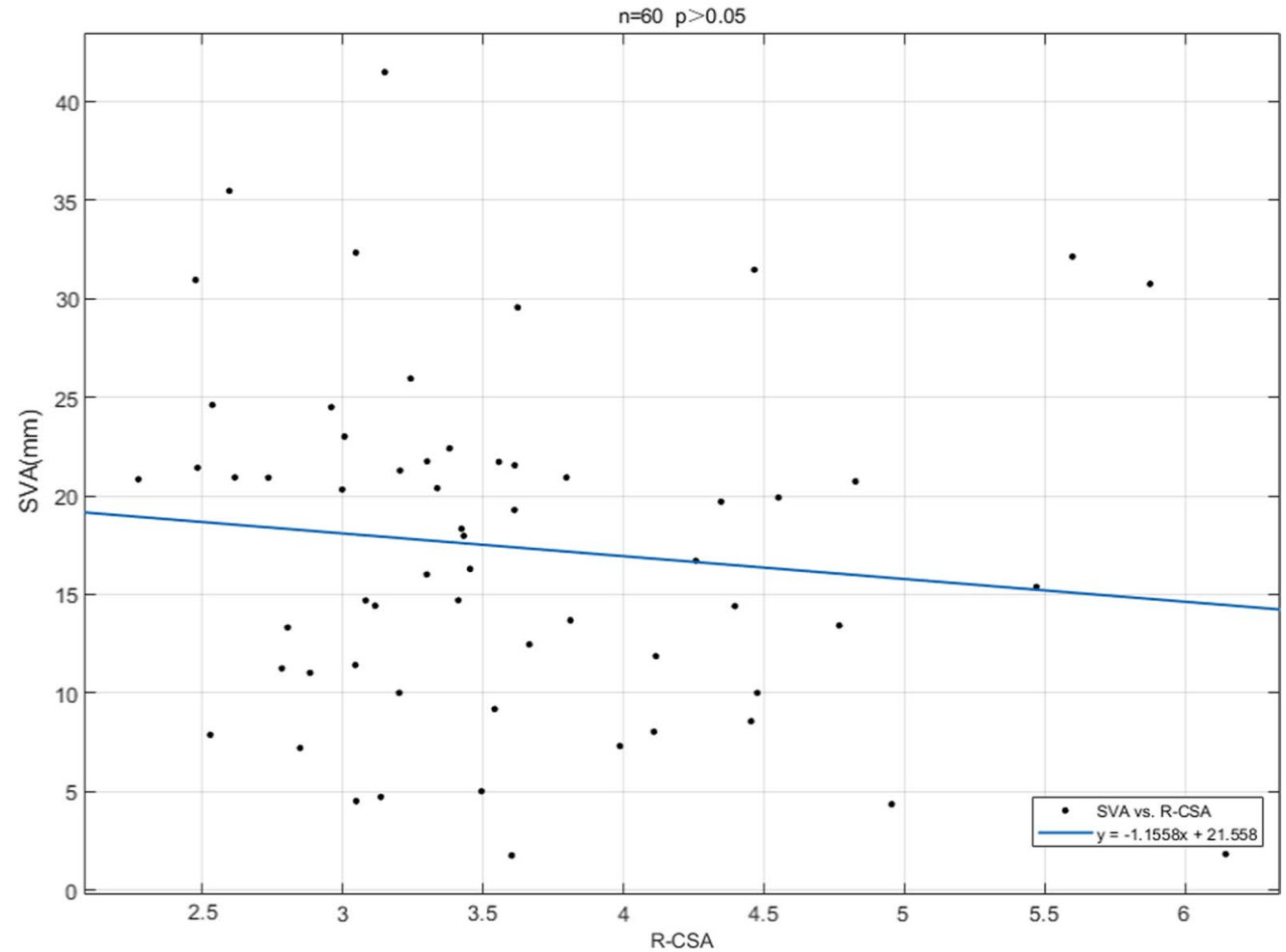

(b)

Fig. 3 Relationship between cervical sagittal parametric and R-CSA 


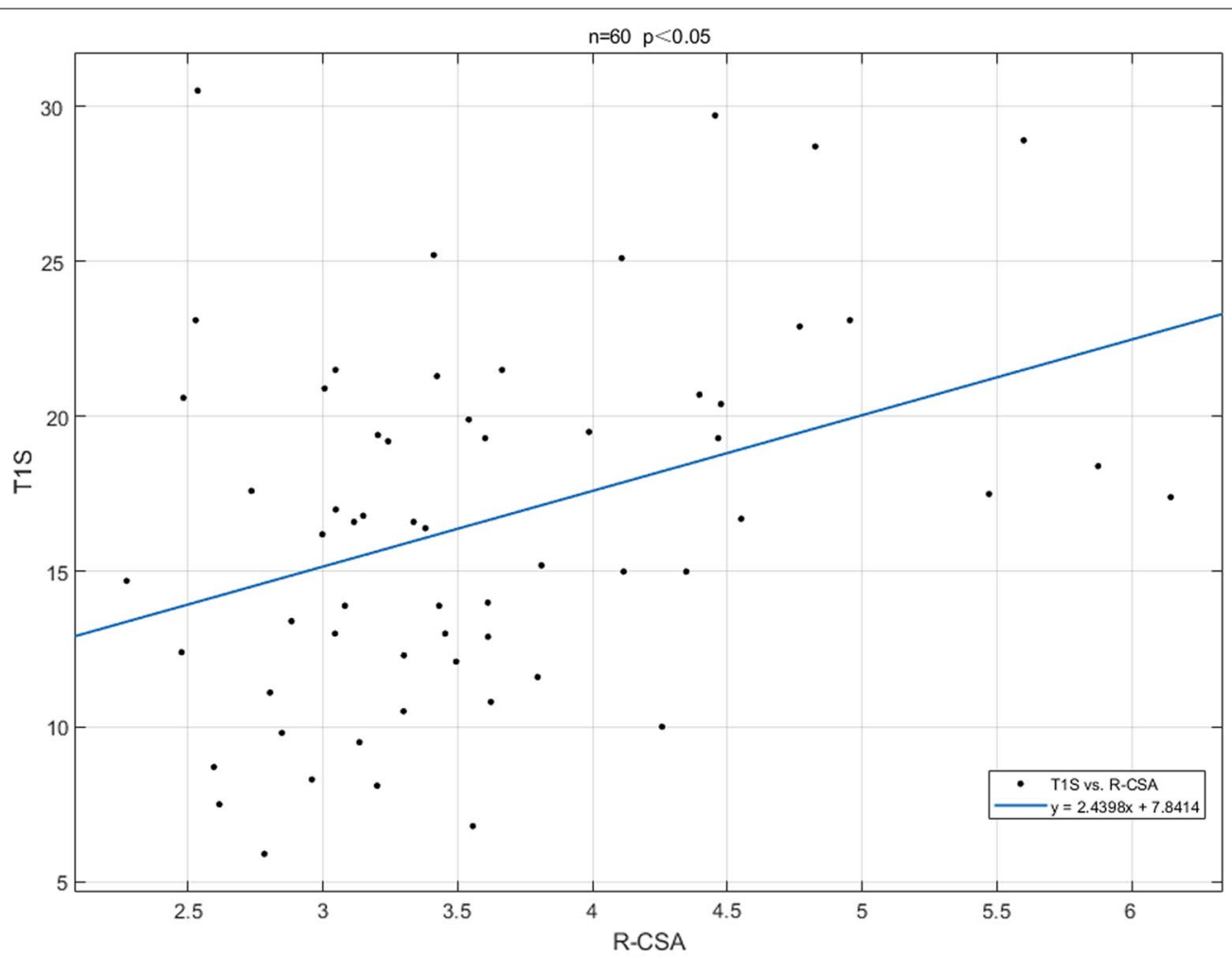

(c)

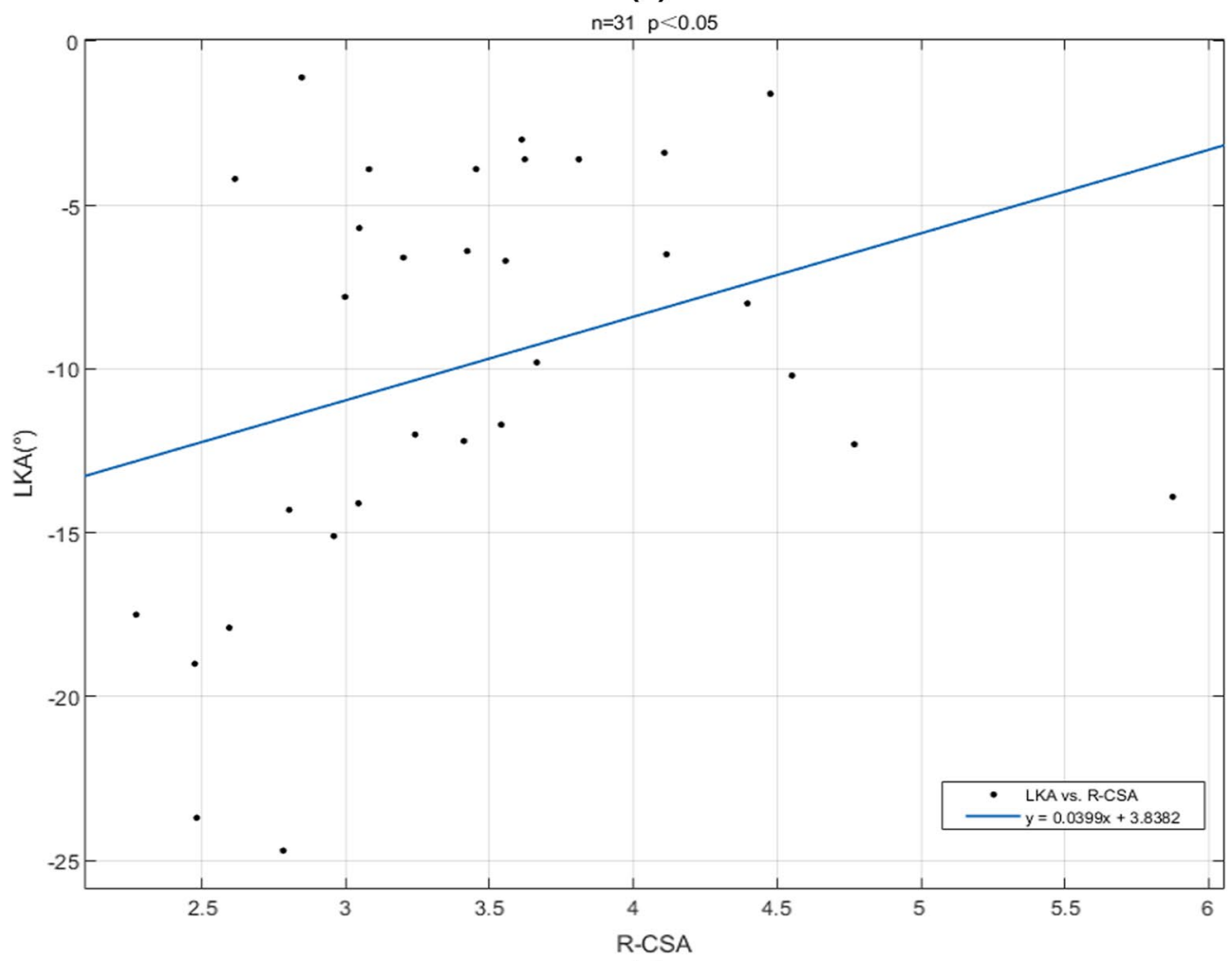

(d)

Fig. 3 continued 


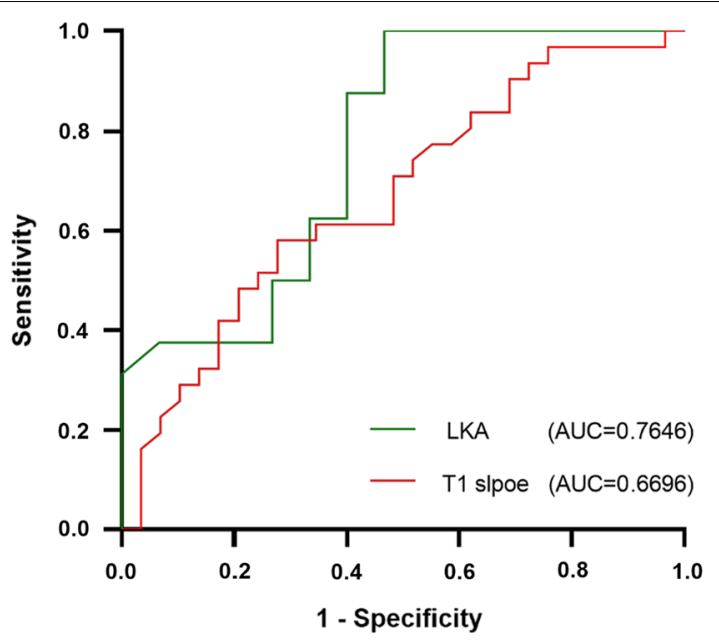

(a)
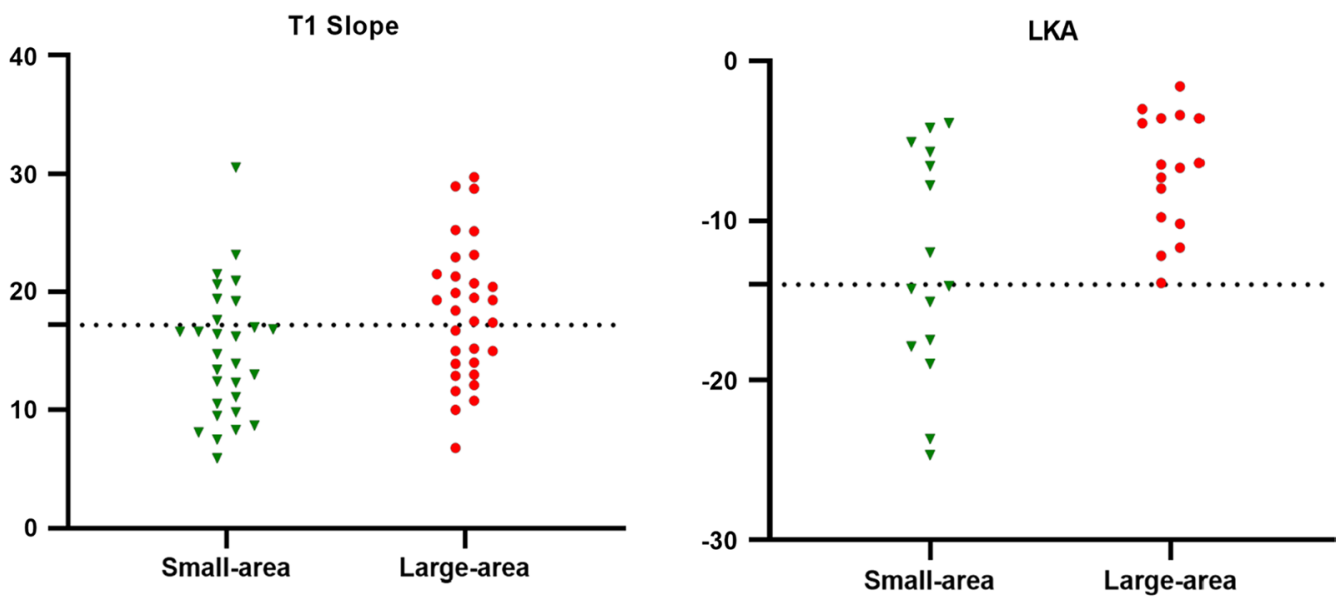

(b)

(c)

Fig. 4 ROC curve of T1 s and LKA

were not obtained after measurement. After analysis, since the number of vertebrae in $\mathrm{C}_{2}-\mathrm{C}_{7}$ did not match the measurement site of muscle (Fig. 3c), we only measured the muscle's CSA at the $\mathrm{C}_{5}-\mathrm{C}_{6}$ level, which does not represent the muscle strength of the entire cervical spine. There was no obvious correlation between the muscle area and the $\mathrm{C}_{2}-\mathrm{C}_{7}$ Cobb angle. Therefore, we defined "local kyphosis" and measured the local kyphosis angle. This analysis showed that in HD patients, LKD tended to occur in the $\mathrm{C}_{3-6}$ segment and was closely related to the CSA of PCEs (the greater the extensor strength, the smaller the LKA, Fig. 3d). We also found that the $\mathrm{C}_{2}-\mathrm{C}_{7}$ Cobb angle of LKD patients was smaller than that of nonLKD patients (Table 3). There was a significant correlation between PCEs strength and cervical spine kyphosis. Most of the vertebrae involved in kyphosis are $C_{3}-C_{6}$, and PCEs atrophy can cause abnormal cervical curvature, especially of the extensor. In HD patients, cervical muscle CSA is smaller than in normal people, and there is flexor and extensor muscle mismatch [24]. We speculate that atrophy of the cervical posterior extensor muscle in HD is a reason for abnormal cervical sagittal alignment.

\section{Treatment considerations for HD}

We show for the first time an association between PCEs and cervical kyphosis in HD patients. Neck muscles are crucial in maintaining stability of the cervical spine. The relationship between neck muscles and cervical spine curvature has been shown in some patients with nonHirayama disease. PCEs weakness is a cause of adolescent idiopathic kyphosis [38]. Extensor muscle strength is weaker than flexor muscle strength in people with poor cervical curvature, as has been reported for HD [24]. The cervical spine is associated with PCEs, similar 
to "bow" and "string." Numerous studies have highlighted the importance of strengthening muscles for spinal sagittal balance [11, 28, 39]. After analyzing the ROC curve and determining the cutoff value, T1 slope and LKD had predictive effect on the R-CSA value. From the result and Fig. 4, it is clear that the LKD is the most sensitive index among the two indices. However, its specificity is comparatively low. For patients with LKD or with small LKA (less than $-14^{\circ}$ ), we hope that they will strengthen the back of the neck muscles. Based on the above studies, we believe that strengthening PCEs should be an important part of HD treatment.

\section{Limitations}

There are some limitations in this study. First, the lack of patients made our data not meet the normality criteria, so we could only use rank correlation, which reduces the level of evidence. Second, the study is limited by its retrospective nature as it lacks healthy controls. Thus, further studies are needed to support the theory we put forward. Finally, only the $\mathrm{C}_{5}-\mathrm{C}_{6}$ level was selected for the muscle area and a simplified measurement method was used, not the true cross-sectional area of the entire back of the neck muscles. Because some parameters of the cervical spine sagittal position were used to evaluate the overall condition of the cervical spine, and CSA does not represent the overall cervical extensor, even partial adjustment of the measurement indicators may affect our results.

\section{Conclusion}

In patients with Hirayama disease, the strength of posterior cervical extensors and cervical sagittal alignment are closely related. The local kyphosis angle can be used as a reference for the strength of posterior cervical extensors. These results indicate the weakness of PCEs, which may predispose the cervical spine of HD patients to a less stable situation. Therefore, patients with Hirayama disease should strengthen the exercise of the PCEs.

\section{Abbreviations \\ CSA: Cross-sectional area; HD: Hirayama disease; MRI: Magnetic resonance imaging; R-CSA: Relative cross-sectional area; ROI: Region of interest; SEs: Superficial extensors; DEs: Deep extensors; PCEs: Posterior cervical extensors; VBA: Vertebral body area; LKD: Local kyphotic deformity.}

\section{Acknowledgements}

We thank the support from colleagues in our department.

\section{Authors' contributions}

$Y T$ and LX wrote the main manuscript text and collected the data, and HW and $J$ f prepared all figures and tables. All authors reviewed the manuscript. All authors read and approved the final manuscript.
Funding

This study was supported by grants from Clinical Research Plan of SHDC (No. SHDC2020CR4030) and Clinical Technology Innovation Project of SHDC (No. SHDC12019X26).

\section{Availability of data and materials}

The dataset used and/or analyzed during the current study is available from the corresponding author on reasonable request.

\section{Declarations}

\section{Ethics approval and consent to participate}

The study was approved by the institutional ethics board (No: 2021-582, Institutional Review Board of Huashan Hospital, Fudan University) and performed in accordance with the ethical standards of the 1964 Declaration of Helsinki as revised in 2000 and those of Good Clinical Practice. All patients gave written informed consent. Participants under the age of 16 have obtained written informed consent from their parents or guardians.

\section{Consent for publication}

Patients signed informed consent regarding publishing their data and photographs.

\section{Competing interests}

The authors declare that they have no competing interests.

Received: 6 November 2021 Accepted: 30 December 2021

Published online: 15 January 2022

\section{References}

1. Hirayama K. Juvenile muscular atrophy of unilateral upper extremity (Hirayama disease)--half-century progress and establishment since its discovery. Brain and nerve = Shinkei kenkyu no shinpo. 2008;60(1):17-29.

2. Antonioni A, Fonderico M, Granieri E. Hirayama disease: a case of an Albanian Woman clinically stabilized without surgery. Front Neurol. 2020;11:183.

3. Bogoni M, Teixeira BCA, Cioni M. Rare occurrence of Hirayama disease in Brazil. Arq Neuropsiquiatr. 2019;77(5):370-1.

4. Finsterer J, Loscher W, Wanschitz J, Baumann M, Quasthoff S, Grisold W. Hirayama disease in Austria. Joint Bone Spine. 2013;80(5):503-7.

5. Witiw CD, O'Toole JE. Electric shocks and weakness of the right hand in a young man: Hirayama disease. The Lancet. 2019;394(10199):684.

6. Song J, Cui ZY, Chen ZH, Jiang JY. Analysis of the effect of surgical treatment for the patients with Hirayama disease from the perspective of cervical spine sagittal alignment. World Neurosurg. 2020;133:e342-7.

7. Wang HL, Wu YW, Song J, Jiang JY, Lu FZ, Ma XS, et al. Cortical activation changes in Hirayama disease after anterior cervical decompression and fusion. World Neurosurg. 2018;116:e588-94.

8. Paredes I, Esteban J, Ramos A, Gonzalez P, Rivas JJ. A severe case of Hirayama disease successfully treated by anterior cervical fusion. J Neurosurg Spine. 2014;20(2):191-5.

9. Zhang H, Wang S, Li Z, Shen R, Lin R, Wu W, et al. Anterior cervical surgery for the treatment of Hirayama disease. World Neurosurg. 2019;127:e910-8.

10. Xu X, Han H, Gao H, Hou C, Fan D, Fu Y, et al. The increased range of cervical flexed motion detected by radiographs in Hirayama disease. Eur J Radiol. 2011;78(1):82-6.

11. Passias PG, Segreto FA, Bortz CA, Horn SR, Frangella NJ, Diebo BG, et al. Fatty infiltration of cervical spine extensor musculature: is there a relationship with cervical sagittal balance? Clin Spine Surg. 2018;31(10):428-34

12. Panjabi MM, Cholewicki J, Nibu K, Grauer J, Babat LB, Dvorak J. Critical load of the human cervical spine: an in vitro experimental study. Clin Biomech (Bristol, Avon). 1998;13(1):11-7.

13. Song J, Wang HL, Zheng CJ, Jiang JY. Risk factors for surgical results of Hirayama disease: a retrospective analysis of a large cohort. World Neurosurg. 2017;105:69-77. 
14. Yoon SY, Moon HI, Lee SC, Eun NL, Kim YW. Association between cervical lordotic curvature and cervical muscle cross-sectional area in patients with loss of cervical lordosis. Clin Anat. 2018;31(5):710-5.

15. Blazevich AJ, Coleman DR, Horne S, Cannavan D. Anatomical predictors of maximum isometric and concentric knee extensor moment. Eur J Appl Physiol. 2009;105(6):869-78.

16. Jones EJ, Bishop PA, Woods AK, Green JM. Cross-sectional area and muscular strength: a brief review. Sports Med. 2008;38(12):987-94.

17. Thakar S, Mohan D, Furtado SV, Sai Kiran NA, Dadlani R, Aryan S, et al. Paraspinal muscle morphometry in cervical spondylotic myelopathy and its implications in clinicoradiological outcomes following central corpectomy: clinical article. J Neurosurg Spine. 2014;21(2):223-30.

18. Hou X, Lu S, Wang B, Kong C, Hu H. Morphologic characteristics of the deep cervical paraspinal muscles in patients with single-level cervical spondylotic myelopathy. World Neurosurg. 2020;134:e166-71.

19. Wang HL, Zheng C, Jin X, Lyu F, Ma XS, Xia X, et al. The Huashan diagnostic criteria and clinical classification of Hirayama disease. Chin J Orthop. 2019;39(8):458-65 (in Chinese).

20. Nascimento OJ, Freitas MR. Non-progressive juvenile spinal muscular atrophy of the distal upper limb (Hirayama's disease): a clinical variant of the benign monomelic amyotrophy. Arq Neuropsiquiatr. 2000;58(3B):814-9.

21. Watanabe K, Hasegawa K, Hirano T, Endo N, Yamazaki A, Homma T. Anterior spinal decompression and fusion for cervical flexion myelopathy in young patients. J Neurosurg Spine. 2005;3(2):86-91.

22. Lyu F, Zheng C, Wang H, Nie C, Ma X, Xia X, et al. Establishment of a clinician-led guideline on the diagnosis and treatment of Hirayama disease using a modified Delphi technique. Clin Neurophysiol. 2020;131(6):1311-9.

23. Sun C, Xu G, Zhang Y, Cui Z, Liu D, Yang Y, et al. Interobserver and intraobserver reproducibility and reliability of the Huashan clinical classification system for Hirayama Disease. Front Neurol. 2021;12:2181.

24. Li Z, Zhang W, Wu W, Wei C, Chen X, Lin J. Is there cervical spine muscle weakness in patients with Hirayama disease? A morphological study about cross-sectional areas of muscles on MRI. Eur Spine J Off Publ Eur Spine Soc Eur Spinal Deform Soc Eur Sect Cerv Spine Res Soc. 2020;29(5):1022-8.

25. Le Huec JC, Thompson W, Mohsinaly Y, Barrey C, Faundez A. Sagittal balance of the spine. Eur Spine J. 2019;28(9):1889-905.

26. Ling FP, Chevillotte T, Leglise A, Thompson W, Bouthors C, Le Huec JC. Which parameters are relevant in sagittal balance analysis of the cervical spine? A literature review. Eur Spine J. 2018;27(Suppl 1):8-15.

27. Murata K, Kenji E, Suzuki H, Takamatsu T, Nishimura H, Matsuoka Y, et al. Spinal Sagittal Alignment in Patients With Dropped Head Syndrome. Spine (Phila Pa 1976). 2018;43(21):E1267-E73.

28. Wen BT, Liu BG. Association between changes in sagittal X-ray measurements and neck extensor muscle atrophy after cervical laminoplasty. Neurochirurgie. 2020;66(6):442-6.

29. Kwon B, Kim DH, Marvin A, Jenis LG. Outcomes following anterior cervical discectomy and fusion: the role of interbody disc height, angulation, and spinous process distance. J Spinal Disord Tech. 2005;18(4):304-8.

30. Lan Z, Huang Y, Xu W. Relationship between T1 slope minus C2-7 lordosis and cervical alignment parameters after adjacent 2-level anterior cervical diskectomy and fusion of lower cervical spine. World Neurosurg. 2019;122:e1195-201.

31. Kuo YH, Kuo CH, Chang HK, Fay LY, Tu TH, Chang CC, et al. The effect of T1-slope in spinal parameters after cervical disc arthroplasty. Neurosurgery. 2020;87:1231-9.

32. Sun J, Zhao HW, Wang JJ, Xun L, Fu NX, Huang H. Diagnostic value of T1 slope in degenerative cervical spondylotic myelopathy. Med Sci Monit. 2018;24:791-6.

33. Lee S-H, Kim K-T, Seo E-M, Suk K-S, Kwack Y-H, Son E-S. The influence of thoracic inlet alignment on the craniocervical sagittal balance in asymptomatic adults. J Spinal Disord Tech. 2012;25(2):E41-7.

34. Virk S, Lafage R, Elysee J, Louie P, Kim HJ, Albert T, et al. The 3 sagittal morphotypes that define the normal cervical spine: a systematic review of the literature and an analysis of asymptomatic volunteers. J Bone Joint Surg Am. 2020;102(19):e109.

35. Zhang J, Buser Z, Abedi A, Dong X, Wang JC. Can C2-6 cobb angle replace $C 2-7$ cobb angle? An analysis of cervical kinetic magnetic resonance images and X-rays. Spine (Phila Pa 1976). 2019;44(4):240-5.
36. Harrison DE, Harrison DD, Cailliet R, Troyanovich SJ, Janik TJ, Holland B. Cobb method or Harrison posterior tangent method: which to choose for lateral cervical radiographic analysis. Spine. 2000;25(16):2072-8.

37. Wang H, Sun C, Yang S, Jiang J, Lu F, Ma X, et al. Dynamic cervical radiographs in patients with Hirayama disease: an unneglectable factor on the choice of surgery options. World Neurosurg. 2018;114:e433-40.

38. Xiaolong S, Xuhui Z, Jian C, Ye T, Wen Y. Weakness of the neck extensors, possible causes and relation to adolescent idiopathic cervical kyphosis. Med Hypotheses. 2011;77(3):456-9.

39. Hrysomallis C. Neck muscular strength, training, performance and sport injury risk: a review. Sports Med (Auckl, NZ). 2016;46(8):1111-24.

\section{Publisher's Note}

Springer Nature remains neutral with regard to jurisdictional claims in published maps and institutional affiliations.
Ready to submit your research? Choose BMC and benefit from:

- fast, convenient online submission

- thorough peer review by experienced researchers in your field

- rapid publication on acceptance

- support for research data, including large and complex data types

- gold Open Access which fosters wider collaboration and increased citations

- maximum visibility for your research: over $100 \mathrm{M}$ website views per year

At BMC, research is always in progress.

Learn more biomedcentral.com/submissions 